\title{
El problema del gobierno: una procedencia pastoral de la gubernamentalidad
}

\author{
The government problem: a pastoral origin of governmentality
}

O problema do governo: uma procedência pastoral da governamentalidade

Lic. Carlos Ramírez Vargas* y Lic. Cristopher Yáñez-Urbina**

\section{RESUMEN}

El artículo profundiza acerca de la procedencia pastoral de la Palabras clave: gugubernamentalidad moderna. Se desarrolla desplazando la "hipótesis griega" como la cuna del arte de gobernar, por la indagación realizada por Foucault en torno a los Padres de la Iglesia y su relación con las culturas egipcia, asiria, mesopotámica y hebrea bernamentalidad, pastoral, Panóptico, tecnologías del yo en torno al paradigma del Dios-pastor y la indexación de las técnicas y códigos del mundo griego. Se concluye que las técnicas y tecnologías de poder elaboradas por el cristianismo, lejos de desaparecer, se indexan, acoplan y relevan al interior de un nuevo conjunto estratégico. Primero como raison d'État y luego en torno al sujeto-objeto que se denomina "población". Por tanto, la tesis de la secularización se ve cuestionada y comprendida en lo que Foucault denomina "tecnologías de gobierno" en la modernidad.

\section{SUMMARY}

The article delves into the pastoral origin of modern governmenKeywords: tality. It displaces the "Greek hypothesis" as the cradle of the art governmentality, of governing, through investigations done by Foucault about the pastoral,

\footnotetext{
* Chileno. Licenciado en Ciencia Política, Universidad de Artes y Ciencias Sociales. Doctorando en Filosofía, Universidad de Chile. Magíster en Comunicación Política, Universidad de Chile. Contacto: carlramirez@ug.uchile.cl https://orcid.org/0000-0002-5719-4569

** Chileno. Licenciado en Psicología, Universidad de Santiago de Chile. Doctorando en Psicología, Pontificia Universidad Católica de Valparaíso. Magíster en Comunicación Política, Universidad de Chile. Contacto: cristopher.urbina@usach.cl http://orcid.org/0000-0001-7171-9686
} 
Fathers of the Church and their relationship with the Egyptian, Assyrian, Mesopotamian and Hebrew cultures around the paradigm of God-shepherd and by indexing the techniques and codes of the Greek world. It concludes that the techniques and technologies of power developed by Christianity, far from disappearing, are indexed, coupled and exalted within a new strategic context. First as raison d'État and then around the subject-object called "population". Therefore, the secularization thesis is questioned and understood in what Foucault calls "technologies of government" in modernity.

\section{RESUMO}

$\mathrm{O}$ artigo aprofunda a procedência pastoral da governamentalidade moderna. Desenvolve-se deslocando a "hipótese grega" como o berço da arte de governar, pela indagação realizada por Foucault sobre os Padres da Igreja e sua relação com as culturas egípcia, assíria, mesopotâmica e hebreia sobre o paradigma do Deus-pastor e a indexação das técnicas e códigos do universo grego. Conclui-se que as técnicas e tecnologias de poder elaboradas pelo cristianismo, longe de desaparecer, são indexadas, acopladas e relevadas no interior de um novo conjunto estratégico. Primeiro como raison d'État e então sobre o sujeito-objeto que se denomina "povo". Portanto, a tese da secularização é questionada e compreendida no que Foucault denomina "tecnologias de governo" na modernidade.
Panopticon, technologies of the self

Palavras-chave: governamentalidade, pastoral, Panóptico, tecnologias do eu 


\section{Introducción}

La publicación del libro Vigilar y castigar por parte de Michel Foucault, en 1975, acarreó consigo la extendida lectura que circunscribe la analítica de las sociedades en el marco del desarrollo de las instituciones de encierro y las disciplinas (Foucault 2018). Lectura problematizada por Gilles Deleuze en la cátedra ¿Qué es un acto de creación?, dictada en la Escuela Superior de Oficios de Imagen y Sonido en 1987, donde señaló enfáticamente que:

...las sociedades disciplinarias tenían necesidad de esos lugares [de encierro]. Pero esto creó ambigüedad en algunos lectores de Foucault que creyeron que éste era su pensamiento último. Evidentemente, no es así.

Foucault no creyó jamás, lo ha dicho claramente, que estas sociedades fueran eternas. Es más, él pensaba que nosotros entrábamos en una sociedad nueva. Por supuesto hay muchos restos de sociedades disciplinarias y por años y años (Deleuze 2012 13).

En esta línea, durante 1978 dictó Foucault una breve conferencia en la Universidad de Vincennes, en la que, como era costumbre para el francés, puso en entredicho sus anteriores trabajos y exhortó al público a hacer el gesto teórico, político y ético de no sucumbir ante la comodidad de la hipótesis que podría denominarse como la del "siempre igual y así por siempre" de los análisis y teorías del orden social (Foucault 1991). Por lo tanto, el análisis del poder, con la rigurosidad que la materia amerita, no recae en una esquemática "jurídico-discursiva" de los universales condenados a repetirse eterna y monótonamente, sino que en las relaciones móviles que se cristalizan, colapsan, acoplan, relevan y reticulan en el espacio-tiempo (Foucault 2014a).

La pregunta que Foucault lanza al público (1991) nos dirige a interrogarnos respecto del denominado "orden social" y se resume de la siguiente manera: "cuáles son sus especificidades y qué lo diferencia [el orden 'actual'] de lo que podía ser el orden en los regímenes precedentes" (136). Lo anterior es una interrogación por lo contemporáneo que no se corresponde con un análisis de lo mediato, sino por la procedencia o, en palabras de Deleuze (1990): “la configuración de lo que somos y dejamos de ser, en tanto que lo actual es el esbozo de lo que 
vamos siendo" (159-160). Dicho de otra forma, una pregunta arqueológica, por los estratos, y una pregunta genealógica, por las estrategias (Foucault 1995), ambas como interrogación de la experiencia real de una época dada (Deleuze 1987).

En esta línea, Foucault se pregunta por la mantención del orden público como "seguridad interior" durante el siglo XIX y buena parte del siglo XX, el cual estuvo marcado por el desarrollo de las tecnologías disciplinarias (Foucault 1991) ceñidas al Panóptico, aquel paradigmático edificio diseñado por el abogado utilitarista Jeremy Bentham, como diagrama exhaustivo, constante y limitativo de un cuerpo-máquina (Foucault 2018). No obstante, es recién en su curso del College de France de los años 1977 y 1978, conocido como Seguridad, territorio, población, en el que desarrolla el neologismo de "gubernamentalidad" para nombrar todo un campo de saber-poder que se preguntará por las técnicas y tecnologías de poder que el moderno Estado-nación desarrolló y tomó de la larga tradición del occidente cristiano respecto del gobierno de los hombres (Foucault 2006).

De tal manera, profundiza sobre lo que él denomina como "dispositivos de seguridad" desarrollados en Europa a mediados del siglo XVIII cuando, con el fin de las monarquías absolutas y los restos del feudalismo, comienzan a emerger las bases de lo que hoy comprendemos por "Estado moderno". Estos dispositivos se definen por no estar sujetos a la rúbrica de la prohibición y lo obligatorio, sino en el elemento de la regulación de la realidad; una realidad que se asume como finita, dispersa y que luego se pliega en el sujeto y su historia. Asimismo, Foucault (2006) señala que los dispositivos securitarios toman distancia de los dispositivos disciplinares, en cuanto estos últimos se centran en una normación de la conducta por medio de reglamentos a los cuales se somete al individuo; sin embargo, las mutaciones técnicas y tecnológicas no se reemplazan en una suerte de progreso lineal.

Lo anterior permite anudar los dispositivos de seguridad con los saberes disciplinares, e incluso soberanos, en un triángulo que articula en la tensión de sus líneas el problema del gobierno (Foucault 2006), cuestión que es atravesada por una "racionalidad"1 más fundamental

1 Para un análisis detallado de la idea de "racionalidad" en la obra de Michel Foucault, consultar el pormenorizado análisis de Santiago Castro-Gómez (2010). El autor 
que la de extraer o cuadricular, y que es caracterizada por Foucault (2008) como "tecnologías del yo", es decir, el problema a la pregunta ¿cómo debemos gobernarnos y ser gobernados?

En la tradición teórico-política de occidente, el problema del gobierno nos reenvía reiteradamente a lo que podría ser denominado como la "hipótesis griega". Sin embargo, aunque en la lectura de Foucault (2011) la problemática del gobierno ocupa un lugar importante en la Grecia clásica y en la experiencia del mundo griego y romano (Foucault 2003), ésta se encontraba orientada a otros fines, los que paulatinamente posibilitaban el ejercicio autónomo del gobierno de sí y de los otros a través de un gobierno indirecto. En este encuadre, es con el desarrollo de la pastoral, por parte de los Padres de la Iglesia, que el acompañamiento reviste características diferenciadas, en cuanto "la dirección cristiana (...) tiene por objetivo la renuncia a la voluntad" (Foucault 2019 147) para inscribirse en una conducción completa y perpetua de los procesos de subjetivación y de la conducta.

Considerando este arco problemático, el presente artículo profundiza respecto de la procedencia de la gubernamentalidad, enlazada al desarrollo de la pastoral cristiana como clave de lectura, que posibilita la comprensión de una serie de técnicas y tecnologías de gobierno de nuestra actualidad en sus dimensiones individualizantes y masificantes. Con ello pretendemos dar cuenta no solamente del desarrollo de un conjunto de técnicas y tecnologías, sino que consignar cómo adquirieron consistencia propia e independiente de la dogmática cristiana y la institución eclesial, para dispersarse en un sinnúmero de tecnologías desarrolladas por la modernidad.

realiza, con base en la obra de Max Weber y su recibimiento por Jürgen Habermas, una distinción exhaustiva del uso weberiano-habermasiano del término, de y la forma en la que es utilizado por Michel Foucault. Al respecto señala: "Los diferentes 'regímenes de prácticas' son vistos por Foucault como animados por racionalidades singulares y heterogéneas, y, en suma: el concepto de 'racionalidad' es utilizado por Foucault para referirse al funcionamiento histórico de prácticas que se insertan en ensamblajes de poder. Tales conjuntos de prácticas son 'racionales' en la medida en que proponen unos 'objetivos' hacia los cuales debe ser dirigida la acción, la utilización calculada de unos 'medios' para alcanzar esos objetivos y la elección de unas determinadas 'estrategias' que permitirán la eficaz articulación entre medios y fines o, en su defecto, el 'uso' de los 'efectos' imprevistos para un replanteamiento de los propios fines" (34). 


\section{Una periodización de la gubernamentalidad}

Luego de la publicación del primer volumen de la Historia de la sexuali$d a d^{2}$, Michel Foucault realiza una seguidilla de digresiones genealógicas y arqueológicas con el fin de abordar la relación que se establece entre poder y verdad. La pregunta por el modo, los fines y la legitimidad de la conducción de los hombres, lo llevará a interrogarse por el concepto de "gobierno" y su deriva individualizante y masificante - o totalizanteen la historia de Occidente. Saberes y poderes que se coagulan en los denominados dispositivos securitarios a mediados del siglo XVIII.

Siguiendo el trabajo de Frédéric Gros, podemos agrupar en cuatro épocas el devenir gubernamental en Occidente y el tema de la seguridad. La primera época está signada por el desarrollo de un conjunto de corpus filosóficos que se desplegaron en la época greco-romana, que abordan el problema del gobierno de sí y de los otros. Siendo así, Gros señala que el problema de la seguridad y el gobierno de sí en la filosofía griega y romana, fundamentalmente entre los escépticos, estoicos, epicúreos y cínicos, corresponde con el desarrollo del tema de la ataraxia o la securitas ${ }^{3}$. Dependiendo de la escuela filosófica, esta pasará por: una renuncia al juicio, en la que la seguridad será comprendida como la serenidad que genera el desapego y la indiferencia, como en el caso de los escépticos; el ejercicio activo de "cristalizar la felicidad pura de existir, de hacer de ella un sentimiento siempre a disposición" (Id. 277), como en el caso de los epicúreos; o el desarrollo de un conjunto de rutinas de ejercicios físicos y espirituales, en los cuales el candidato se somete a sí mismo a la ascesis, a la meditación de la muerte, etc., con el fin de alcanzar un dominio de sí, de su cuerpo, sus emociones, sus pensamientos, de tal modo que las variaciones y sobresaltos del mundo no afecten ese estado de "igualdad de humor" (Ibid.), como en el caso de los estoicos.

2 Michel Foucault, en el primer volumen de la Historia de la sexualidad: La voluntad de saber de 1976, muestra cómo la sexualidad en occidente articula la relación entre poder, saber y subjetividad, toda vez que el sexo, como dominio epistémico e interioridad del sujeto moderno, permite acceder a la verdad de sí. La sexualidad se articula como fondo de sí y superficie de agarre de las relaciones de poder. Por eso el saber de la sexualidad se presenta como una voluntad de saber, que prescribe e inscribe sobre el cuerpo y su subjetividad una voluntad de escudriñamiento que le permite acceder a la verdad. 3 El vocablo latino securitas, tal como lo señala Frèdrìc Gros, se descompone en sine cure, "es decir: sin perturbación, sin cuidado" (276). 
La segunda época está signada por la relación entre gobierno e imperio. El problema pasará del gobierno de sí al gobierno de los otros, sin que el primer problema sea subsumido jamás por el segundo. Este tema se desarrolla mayormente durante la Edad Media en torno al mito-político del imperio de los últimos días, que es una adaptación remozada del milenarismo cristiano y la pax romana. La conjunción entre imperio, seguridad y fin de la Historia será una idea que asolará el pensamiento político occidental, al punto de considerar que la "seguridad auténtica sólo puede ser obtenida por la constitución de un espacio político y cultural homogéneo, y por la exclusión o la destrucción de todas las figuras del Otro" (Id.280), cuestión que se expresa en la condición katechontica ${ }^{4}$ del Imperio Cristiano como freno del Anticristo (Cacciari). Estas ideas se expresarán en la modernidad a través de la filosofía y la ciencia positiva como conclusión de la Historia, por medio de un retorno al inicio o la culminación de la perfección humana debido al progreso tecno-científico (Noble).

La tercera gran época del gobierno y la seguridad es, sin duda, el desarrollo del pensamiento contractualista, operado por Hobbes, Locke, Spinoza y Rousseau, entre mediados del siglo XVII y finales del siglo XVIII, el cual también es posible de identificar con el inicio de la ruptura de la episteme clásica (Foucault 1968). A esta época también Foucault (2006) la denominó el "momento de la emergencia de la razón de Estado", la cual consiste en el desarrollo de un conjunto de saberes, ya no referidos al problema soberanista del Príncipe y el orden enunciativo de las riquezas (mantención del dominio de la tierra y las técnicas de extracción), sino de una ciencia que intenta delimitar los contornos inmanentes de un Estado en forma (legítima y racional) en un contexto internacional. Los dispositivos securitarios están signados por el desarrollo de las tecnologías denominadas "policíacas", encargadas de regular el desarrollo "natural" ${ }^{5}$ de una nueva figura conceptual

4 El concepto técnico de katechon, en la literatura cristiana, se refiere al poder que frena la venida del Anticristo, lo cual es al mismo tiempo una paradoja, en tanto la venida del Anticristo es la condición de posibilidad para la vuelta del Mesías y la venida del reino celestial (Cacciari).

5 Esta "naturaleza" tendrá una ambivalencia constitutiva, en tanto se refiere a una "naturaleza" insuflada por un cierto "positivismo" propio del desarrollo de las ciencias naturales y etnológicas de finales del siglo XVIII, pero también por una particular interpretación antropológica firmemente arraigada en los trabajos del pensamiento contractualista de la misma época. Toda antropología es siempre normativa. Para el caso del 
llamada "población". Estos dispositivos deben garantizar el desarrollo de una "buena población", al tiempo que esto permite un Estado fuerte en el contexto internacional. Con el fin del sueño milenarista de la reconstrucción del Gran Imperio Cristiano, el Estado adquiere una consistencia propia como sujeto político. Por tanto, la seguridad como tecnología y el gobierno como campo enunciativo son vistos como una ciencia que propugna por la estabilidad, la salud y la buena administración de la población como condición de posibilidad del desarrollo del Estado.

Finalmente, siguiendo a Gros, la cuarta época podría ser denominada "biopolítica", la cual está signada por

...una transformación muy profunda en la idea de seguridad; esa transformación es visible en una nueva red discursiva, a saber: una serie de enunciados como esas relativas a la "seguridad humana", a la "bioseguridad", a la "seguridad global" o incluso a la "seguridad afectiva" (284).

Todo este nuevo campo enunciativo no soslaya los anteriores, sino que los integra como flujos, tema que ya está presente en las tecnologías policíacas de la "razón de Estado", las cuales están encargadas de permitir el flujo adecuado de mercancías y cuerpos. La época actual, la cual para Gros es la época biopolítica, intensifica e identifica la seguridad con los flujos ${ }^{6}$. El flujo se torna el objeto mismo del régimen de veridicción de la seguridad, temas como "flujo de alimentos, flujo de energía, pero también de imágenes o flujo de informaciones (y, por extensión, se hablará de seguridad vial o seguridad informática) toman el relevo de la seguridad de la "razón de Estado" (Foucault 2006). Un Estado en forma, es un Estado que asegura los diversos flujos que com-

desarrollo de la "razón de Estado", éste tendrá la misión de generar un espacio en el que esa antropología sea posible de desarrollar y prosperar. Esto permite a Marx, en Sobre la cuestión judía, señalar que: "La seguridad es el más alto concepto social de la sociedad burguesa, (...) que toda la sociedad existe sólo para garantizar a cada uno de sus miembros la conservación de su persona, de sus derechos y de su propiedad" (149), toda vez que dicha concepción parte de una cierta antropología del individualismo posesivo.

6 Cuestión que es posible de refrendar con base en los análisis que el geógrafo inglés David Harvey (2004) vierte en su libro El nuevo imperialismo. Aquí trabaja la tesis de que el nuevo imperialismo, en oposición al imperialismo definido por la tradición leninista, no trabaja sobre la posesión de los territorios para ampliar los mercados, sino sobre la desposesión por desterritorialización, es decir, el capitalismo torna el problema de los flujos y su desplazamiento como el elemento indispensable para su desarrollo. 
ponen el sistema social. "La genealogía antigua de esta nueva seguridad biopolítica - señala Gros- habría que buscarla en ese fenómeno policial" (286). Retengamos esta última idea, que será desarrollada más adelante.

Una segunda consecuencia, asociada a la seguridad como flujo, se encuentra en los actores que toman el relevo de las tecnologías y saberes de la "razón de Estado". Según describe Gros, hay un proceso de privatización de las dos grandes funciones que abarcó el Estado desde los inicios de la modernidad (finales del siglo XVIII hasta mediados del siglo XX), a saber: la anatomopolítica de los cuerpos individuales (escuelas, hospitales, regimientos, etc.) y la biopolítica de la población desde el punto de vista de su vida biológica (estadística, políticas públicas universales, etc.). Esta función es retomada por organismos internacionales, organizaciones no gubernamentales y empresas privadas, como especialistas en "control de un flujo determinado" (286). Esto abre la aporía que el propio Foucault descubriría en la articulación entre liberalismo, gubernamentalidad y biopolítica, en tanto el liberalismo sería una biopolítica del Estado mínimo. Por lo cual, "lo que resulta asombroso en los nuevos dispositivos de seguridad es, precisamente, que ya no se ordenan según el imperativo de un Estado, sino que, en lugar del Estado, aparece sólo la exigencia de una circulación de flujos" (287).

Una tercera consecuencia de lo anterior, visualizada por Gros, y que lo acerca mucho a los desarrollos realizados por Deleuze (2005) a propósito de las sociedades de control y al colectivo Tiqqun y su hipótesis cibernética, es el cambio en las modalidades de la seguridad. Esta se basaría en "la protección y control de los flujos" (Gros 287), condensados en ciencias como la haptonomía, disciplina neurocientífica y médica, desarrollada luego de la Segunda Guerra Mundial, en la que la seguridad se transforma en control de los flujos a los cuales está expuesto un sujeto a lo largo de su vida. Por ejemplo, flujos alimenticios, flujos de intercambio regulado y flujos de comunicación interpersonal e información transpersonal. Esto marca un cambio con la otrora "razón de Estado", la cual estaba formada por un conjunto de espacios cerrados sobre sí mismos. La época biopolítica está signada por la "trazabilidad", es decir, "poder determinar en cada momento quién se desplaza, dónde viene, a dónde va, lo que él hace allí donde está, y si 
efectivamente tiene acceso a la red en la que se desplaza y si tiene o no prohibición" (Id. 288).

Esto tiene una cuarta consecuencia, asociada a la amplitud del "espacio correlativo" (Deleuze 1987), en la que un conjunto de objetos pasa a formar parte de un orden enunciativo diferente. La seguridad amplía sus objetos y con esto las amenazas, sean climáticas, sanitarias, ecológicas, sociales o políticas ${ }^{7}$. Con esto las categorías políticas modernas implosionan: las distinciones entre interior/exterior, criminal/ enemigo, político/impolítico, ciudadano/terrorista, etc., se vuelven ambiguas y porosas. La sospecha y la victimización generalizadas son los elementos de un régimen securitario basado en el "control de los flujos", es decir:

...control de los desplazamientos y de las comunicaciones, pero un control descentralizado, según redes concurrentes, transnacionales, y que plantea el problema del acceso, es decir, quién tendrá acceso a tal o cual red para controlar o redistribuir tal o cual flujo (Gros 291).

Con estas esquemáticas periodizaciones que propone Gros es posible delinear un conjunto de elementos, como las relaciones entre gobierno de sí, gobierno de los otros, "razón de Estado" y flujos, pero también abren un conjunto de interrogantes a propósito de la genealogía de los dispositivos securitarios y la gubernamentalidad, y cómo estos saberes y tecnologías tan diversas se conectan, relevan, suprimen e intensifican.

En este contexto, es el mismo Gros quien propone que la genealogía de los dispositivos securitarios de la gubernamentalidad biopolítica contemporánea debe ser buscada en las tecnologías policíacas de finales del siglo XVII y la primera mitad del siglo XVIII. Estando de acuerdo en lo grueso con el planteamiento del autor, es necesario contemplar el hecho de que es el propio Foucault quien establece una relación de

$7 \quad$ Esto es lo que muestran Juan Saavedra y Víctor Marchezini en su artículo "Procesos de recuperación posdesastre en contextos biopolíticos neoliberales", en el que abordan los casos de Chile y Brasil - el terremoto de Concepción, en 2010, y las inundaciones que afectaron a Río de Janeiro, en 2011 - para mostrar cómo la biopolítica contemporánea maneja los desastres ambientales como un problema de seguridad en los términos que aquí se han definido. Con lo que consiguen demostrar que la seguridad y su tratamiento son fenómenos posibles de situar histórica y políticamente. 
"procedencia"8 (Foucault 1980) entre estos saberes y tecnologías, y el poder pastoral desarrollado por el cristianismo. Esto es claro, tanto en los cursos de 1978 - que le dedica a la gubernamentalidad, la razón de Estado y los dispositivos securitarios-, como en la conferencia que realizó en 1979 en la Universidad de Stanford Omnes et singulatim. En ambos contextos muestra el autor, con toda claridad, que los elementos constitutivos de la gubernamentalidad moderna y contemporánea deben ser buscados en la pastoral cristiana y su desarrollo "secular".

A propósito de lo anterior se propone el análisis de dichos textos, con el fin de delimitar de mejor manera los objetos, tanto de la gubernamentalidad como de sus relaciones de procedencia con los dispositivos pastorales, y cómo estos articulan tanto las tecnologías de individualización como su envés masificante (totalizante).

\section{Procedencia pastoral de la gubernamentalidad}

En sus clases de 1978, Seguridad, territorio, población, Foucault propone una analítica de la gubernamentalidad, sus implicancias con los dispositivos securitarios y el surgimiento de la figura de la población como sujeto-objeto de esta rúbrica, pero rápidamente se ve llevado hacia la interrogación por las fuentes de lo que define como el "gobierno de los hombres", las cuales se pueden ordenar en torno al poder pastoral y sus rasgos diagramáticos de poder (Deleuze 1987), que consisten en ser un poder que (1) se ejerce sobre una multiplicidad en movimiento; (2) se presenta como benéfico para el rebaño mismo, e (3) individualiza.

En este sentido, en sus clases Foucault va a realizar una serie de distinciones en torno a las diferencias que, en el pensamiento de Platón, particularmente en su diálogo Político, van a marcar la distancia radical entre la téchne del político y la del pastor. En la polis, la téchne o arte del político no es proporcionar bienestar, en el sentido "welfareano"

8 Foucault (1980), en Nietzsche, la genealogía, la historia, de 1971, a propósito de la "procedencia" en el análisis genealógico, señaló que: "La procedencia permite también encontrar bajo el aspecto único de un carácter, o de un concepto, la proliferación de sucesos a través de los cuales (gracias a los que, contra los que) se han formado. La genealogía no pretende remontar el tiempo para restablecer una gran continuidad por encima de la dispersión del olvido. Su objetivo no es mostrar que el pasado está todavía ahí bien vivo en el presente, animándolo aún en secreto después de haber impuesto en todas las etapas del recorrido una forma dibujada desde el comienzo" (13). 
del término, es decir, proporcionar un bienestar material y físico a sus gobernados. Para esto, en la polis griega existen diversas artes encargadas de cada una de estas materias, por ejemplo, el médico para la salud del cuerpo, el maestro para el desarrollo de los jóvenes, el arquitecto para las viviendas y las construcciones, etc. El arte del político o el Rey, que mandata en la polis - y que Platón pone en boca del extranjero-, se asemeja al arte del tejedor'.

Por otro lado, el político actúa sobre un territorio bien delimitado, que es la polis $^{10}$. Además, el "gobierno" se ejerce de manera indirecta por medio de la diké y el entretejido de las diversas artes; a diferencia del pastor, cuyo trabajo se podría denominar como "desterritorializado" e individualizante. Al punto que esto lleva a Foucault a señalar que no le parece claro que la noción de "gobierno" como gobierno pastoral pertenezca a la tradición, al menos, de la Grecia clásica (Foucault 2006 151).

Foucault busca entonces la procedencia de dicha concepción de gobierno en el pensamiento de Oriente Medio, primero en el Oriente precristiano y luego en el Oriente cristiano. Muestra, con una abundante bibliografía, cómo las culturas egipcia, asiria, mesopotámica y hebrea desarrollan una singular teología-política que les sirve como paradigma del gobierno de los hombres. Las ideas del "Dios-pastor" y, por extensión, la del "gobernante-pastor" están en la base de estas concepciones. Sin embargo, Foucault sostiene que en el cristianismo opera una radicalización de dicha tesis. Con la adopción del cristianismo en el año 380 d.C. como religión oficial del Imperio Romano, el pastorado —no como conjunto de creencias ni como institución ecle-

$9 \quad$ Platón pone en boca del extranjero, en su diálogo el Político, su conclusión sobre el arte propio de la actividad política: "Éste es — digámoslo- el fin del tejido de la actividad política: la combinación en una trama bien armada del carácter de los hombres valientes con el de los sensatos, cuando el arte real los haya reunido por la concordia y el amor en una vida común y haya confeccionado el más magnífico y excelso de todos los tejidos, y, abrazando a todos los hombres de la ciudad, tanto esclavos como libres, los contenga en esa red y, en la medida en que le está dado a una ciudad llegar a ser feliz, la gobierne y dirija, sin omitir nada que sirva a tal propósito" (311c).

10 En este mismo sentido, Aristóteles puede señalar al inicio de la Política: "Y el que no puede vivir en comunidad, o no necesita nada por su propia suficiencia, no es miembro de la ciudad, sino una bestia o un dios" (1253a14). Es decir, la ciudad es por definición un espacio delimitado que incluso determina antropológica y ontológicamente la definición del hombre. 
sial- desarrolla un conjunto de técnicas y tecnologías encaminadas a la conducción de la actividad de los hombres ${ }^{11}$, las cuales serán sofisticadas a lo largo de la Edad Media.

Ahora bien, Foucault (2006) toma como punto de partida para sus análisis de la importancia del pastorado para la "historia de la gubernamentalidad", el dictum sentenciado por Gregorio Nacianceno en el siglo IV d.C., cuando define el arte de gobernar a los hombres por medio de la "conducción de la conducta" como "téchne technon, episteme epistemon" (180), es decir, como el arte de las artes y la ciencia de las ciencias. Esto quiere decir que, ya en el siglo IV, mucho antes del saber desarrollado por la "razón de Estado" en el siglo XVII-XVIII, lo que viene a sustituir a la filosofía y a la teología como ciencias de todas las ciencias es el saber del pastor, el cual consiste en "el arte por el cual se le enseña a la gente a gobernar a otros o se le enseña a los otros dejarse gobernar por algunos" (Ibid).

En lo que sigue podemos analizar la racionalidad de los espacios "correlativo" y "complementario" (Deleuze 1987) puestos en juego por la pastoral cristiana. Foucault (2006) los agrupa en cuatro principios. Sin embargo, valga una aclaración en torno a la exposición que prosigue. Lo que importa retener dice relación con el campo complementario, es decir, el campo técnico y tecnológico del poder que articula la pastoral, y no tanto cómo esta se conjuga con la dogmática y las instituciones eclesiales.

El primer principio dice relación con la "responsabilidad analítica" (Foucault 2006), que consiste en que el pastor cristiano asume la responsabilidad absoluta del cuidado de los individuos que componen el rebaño. Para lograr este objetivo se desarrolla un conjunto de técnicas de observancia, tomadas de la tradición epicúrea y estoica, y desarrolladas por el cristianismo. Este espacio complementario está conformado por las técnicas del examen y dirección de conciencia, con las

11 Esto es lo que le permite a Nietzsche en De la genealogía de la moral, de 1887, señalar que la cultura Occidental se bate entre dos almas, la figura del pastor y la del soberano, la conducción a la salvación y la violencia mítica. Al respecto señala: "El símbolo de esta lucha, escrito en caracteres que a lo largo de toda la historia de la humanidad se han mantenido legibles hasta ahora, dice «Roma contra Judea, Judea contra Roma»: —no ha habido hasta ahora acontecimiento más grande que esta lucha, que esta discusión, que este antagonismo a muerte" (480). 
cuales el pastor-gobernante es capaz de medir el progreso individual de cada oveja y enmendar el rumbo de los individuos. Por tanto, el poder se ejerce de manera capilar, continua y directa.

El segundo principio es el de la "transferencia exhaustiva" de la responsabilidad de los conducidos (Foucault 2006). La desgracia del rebaño es también la desgracia del gobernante. Este es un tema que puede ser similar al Edipo de Sófocles; sin embargo, la problemática es inversa, ya que la desgracia que ignora Edipo se convierte en la desgracia de la polis. Por esto, el comportamiento desviado del rebaño, los peligros que le acechan como los males individuales de cada miembro, son la desgracia del gobernante mismo. Las técnicas propias de este principio pasarán por la mortificación de la carne con el objeto de "negociar" la culpa, con lo cual el control de los cuerpos se vuelve un problema capital.

El tercer principio es la "inversión sacrificial" (Foucault 2006), el cual consiste en la condición y la relación vitalicia del pastor para con el rebaño. Esto tiene como consecuencia que la actuación del pastor no se limita a un espacio-tiempo determinado, sino que le acompaña y acompaña al rebaño a lo largo de toda su vida. El pastor, a diferencia del sabio del mundo grecolatino, no busca vivir para sí por medio del cultivo personal, tampoco conforme a las leyes; todo cultivo personal es inmediatamente un cultivo para otro. Incluso, la relación entre ética y obra particular del pastor se encuentra completamente disociada, al punto que en el siglo XIII la leitourgía que ejecuta el pastor no tiene como condición de posibilidad las características éticas de la misma para ser eficiente (Agamben 2012), con lo que el espacio complementario articula un conjunto de técnicas en las que el "Yo" es disociado de su actuación espaciotemporal, ya que el pastor debe actuar en todo momento y en todo lugar.

El cuarto y último principio mencionado por Foucault (2006) durante sus clases es el "principio de la correspondencia alternada", que tiene como consecuencia la articulación de un "espacio público" en el que la economía del gobierno pastoral se juega la conformación de un plano de mutuas dependencias entre pastor y rebaño, entre rebaño y pastor, y entre ovejas y ovejas. Esto debido a que el pastor y sus ovejas deben hacer públicas sus faltas, sus deméritos, sus debilidades, con el propósito de que el rebaño no caiga en el orgullo. Por lo tanto, el "es- 
pacio público" no estará regulado necesariamente por leyes generales, sino que será "coyuntural e individual" (206); una oikonomia de los méritos y los deméritos, más que un nomos que permite el cultivo de la areté.

Este conjunto de principios, con sus espacios correlativos y complementarios, articulan todo un saber y sus diagramas, en los que el ejercicio del poder aparece relacionado a su carácter capilar, continuo y directo en un ejercicio individualizante; como control de los cuerpos y su domesticación; una actuación individualizante pero impersonal en un espacio-tiempo no delimitado de antemano, y la conformación de un "espacio público" no regulado por leyes generales, sino por manuales que son una mezcla de preceptos y la observancia continua de los individuos. Esto es lo que le permite a Foucault aseverar que:

De Wyclif a Wesley, del siglo XIII al siglo XVIII, todas las luchas que culminaron en las guerras de religión eran en lo fundamental contiendas para dilucidar quién tendría el derecho concreto de gobernar a los hombres, gobernarlos en su vida cotidiana, en la minucia y la materialidad que constituyen su existencia, y quién tenía ese poder, a quién se lo debía, como lo ejercía, con qué margen de autonomía para cada uno, qué calificaciones debía tener para imponerlo, qué límites había a su jurisdicción, que recursos podía haber contra él, qué control aplicaban unos sobre otros. Todo esto, esta gran batalla de la pastoralidad, recorrió Occidente (Foucault 2006 178-179).

Lo anterior se comprende si se tiene en consideración que las "contraconductas" 12 que atraviesan la cristiandad durante al menos quince siglos, al mismo tiempo que perseguidas, también fueron negociadas e integradas. Mientras que lo que ponen en tela de juicio los poderes políticos son los límites internos de dicha racionalidad y sus diversas tecnologías, pero no la racionalidad misma del pastorado cristiano (cuestión que es fundamental también en el contractualismo moderno) (Foucault 2007). El gobierno de los hombres como

12 Foucault agrupa en esta categoría: el gnosticismo de los siglos II, III y IV; las rebeliones de los conventos femeninos en el XII por parte de las "Nonnenmystik" renanas; también se puede agregar el conflicto entre franciscanos y papado en el siglo XIII; además del conflicto entre "lolardos", encabezados por Wyclif, y el clero en el siglo XIV, hasta los reformadores y Martín Lutero en el siglo XVI. 
poder pastoral se mantuvo incólume, a pesar de que estas "contraconductas" plantearon un conjunto de técnicas y tecnologías antipastorales.

La crisis de la pastoral cristiana como patrimonio exclusivo de la Iglesia ocurre en el siglo XVI, con la Reforma Protestante, al mismo tiempo que dicha intersección resonará con el desarrollo del mercantilismo, el creciente conflicto campo-ciudad y el nacimiento de los grandes aparatos de Estado. Sin embargo, no sería correcto señalar que el pastorado cede ante el Estado. La tesis de la secularización, popularizada por el weberianismo, que explica muy bien el proceso por medio del cual la institución eclesial fue perdiendo su gran influencia sobre la sociedad, no aclara en modo alguno cómo las tecnologías desarrolladas por el pastorado cristiano se intersectan y son integradas en el nuevo contexto de un mundo desencantado y ceñido al cálculo instrumental. La tesis que elabora Foucault es que, una vez que dichas técnicas y tecnologías se desanclan radicalmente de la estructura eclesial, no solo no desaparecen, sino que son integradas por medio del desarrollo de la "razón de Estado", y en su doble carácter, a saber, como técnicas y tecnologías de individualización de la población, de control de los cuerpos individuales, de intervención capilar continua, en constante desplazamiento sobre el conjunto de la población-rebaño y conformando un "espacio público"13. Tenemos entonces un conjunto de saberes y poderes atravesados por las tecnologías pastorales, ahora configurando las grandes tareas del Estado moderno. Al respecto, señala Foucault (2006):

Y entonces llegamos a la famosa paradoja del pastor que adopta dos formas. Por una parte, el pastor debe tener los ojos puestos sobre todos y cada uno, omnes et singulatim, que va a ser precisamente el gran problema de las técnicas de poder en el pastorado cristiano y

13 Según Arnault Skornicki, la tesis de las mutaciones tecnológicas del poder, elaborada por Foucault, "desactiva sin decirlo la tesis de la secularización" (73), esto porque aquella es "demasiado masiva, transitiva y lineal (...) en una palabra demasiado evolucionista" (Ibíd.). El autor plantea que: "Foucault elabora (...) una perspectiva rizomática y demultiplicadora. De este modo, el retroceso de la iglesia como institución y autoridad no marca ni el achatamiento de lo religioso sobre lo político, ni la espiritualización de este último, sino el desbordamiento de los dispositivos cristianos al margen de la comunidad de fieles e independientemente del clero, llamados a circular capilarmente en el cuerpo social" (Ibíd.). 
de las técnicas de poder, digamos, modernas, tal como se disponen en tecnologías de la población (157).

Lo anterior es lo que muestra Foucault (2008) en su conferencia Omnes et singulatim de 1979. Luego de desarrollar muchos de los puntos ya presentes en sus cátedras del año anterior, señalará que el Estado moderno se erige sobre la base de dos líneas que le son inmanentes: por un lado, el gobierno de los individuos y, por otro, el gobierno de las masas. El pastorado cristiano es una especie de bisagra, "algo que se encuentra a mitad de camino entre el Estado, como tipo de organización política y sus mecanismos, a saber, el tipo de racionalidad implicada en el ejercicio del poder de Estado" (120-121). Esta bisagra entra en relación con la "razón de Estado y la teoría de la policía", es decir, con el desarrollo de los dispositivos securitarios. Por lo tanto, el desarrollo de un conjunto de saberes coherentes con estas mutaciones ya no debía guiarse por modelos ideales que pudieran hallarse en la Naturaleza o la Divinidad, sino que debía guiarse por su objeto mismo: el Estado, el cual ya no debe ser entendido como medio para un fin, sino como fin en sí mismo. El Estado adquiere la consistencia política que permite a su ciencia pensar qué es realmente lo que compone al Estado. Con esto se desbloquea definitivamente la episteme clásica, la cual comprendía el análisis de las riquezas, la historia natural y la gramática como un conjunto de saberes que permitían conocer la consistencia económica, natural y cultural de un Estado (Foucault 1969), y se comienza a dibujar un elemento indispensable: la población, la cual está acompañada por el desarrollo de la estadística como su ciencia mayor. La "razón de Estado" marca un quiebre epistémico, en tanto opera una imposibilidad para conocer el mundo por medio de los métodos de la "analogía" y la sympathia (34-38), lo que para este caso quiere decir que el poder político y sus instituciones no pueden deducir sus funciones y objetivos del orden superficial del Mundo, sino que debe definir el lugar que ocupa el Estado en el gran cuadro de las naciones.

\section{Razón de Estado y el umbral de modernidad política}

El mundo pasa a ser momentáneamente gobernado por leyes, este es el gran aporte epistémico de Copérnico, Kepler o Linneo. El mundo no puede ser comprendido por sus signos, sino por su representación, lo cual implica un lenguaje formalizado tendiente a una mathesis uni- 
versal (Id. 77-82). Con esto ocurre un proceso que abrirá la posibilidad epistémica para que las tecnologías de poder elaboradas por el pastorado, las cuales ya se habían desanclado funcionalmente de las instituciones eclesiales, puedan ser intersecadas con la naciente "razón de Estado". Por esto, no basta con argumentar desde el proceso de secularización, laicización y, finalmente, racionalización del mundo, sino entender que este proceso está guiado por un profundo cambio epistémico que dispone las palabras y las cosas de una manera diversa, lo que permite que las tecnologías centradas en la conducción de la conducta queden ensambladas a tecnologías cuyos fines son muy diversos de los de la pastoral cristiana. El Estado será un nuevo locus, por tanto, no hay una transferencia de funciones de la Iglesia al Estado, ni tampoco un traspaso de valores religiosos a unos racional-instrumentales.

Ahora bien, es esta misma razón de Estado, con sus dispositivos policiales de regulación y aparatos diplomático-militares, la que bloquea sustancialmente el desarrollo de las tecnologías gubernamentales, en tanto el Estado, como fin en sí mismo, centralizará de manera absoluta funciones tales como la economía, por medio de la regulación de la producción de alimentos y la moneda; la salud, por medio del control de la salud pública, y el control de la circulación en los "espacios públicos" para impedir la “vagancia", los desórdenes públicos, pero también la circulación de enfermedades. En este sentido, se puede afirmar que la razón de Estado tomará para sí un conjunto de técnicas y tecnologías de conducción de la conducta desarrolladas por la pastoral cristiana, articuladas ahora en torno al Estado como sujeto-objeto. Sin embargo, los esfuerzos teóricos de las ciencias del Estado y la policía girarán en un vacío constitutivo, ya que si, para la pastoral cristiana, la superficie sobre la cual inscribe sus tecnologías de poder era el rebaño-oveja, ¿cuál será la superficie afectiva sobre la cual intervendrán los dispositivos securitarios?

Foucault (2006 y 2008) muestra, con toda precisión, que el elemento restante en la ecuación de la construcción de los Estados modernos es una superficie de agarre, una interioridad más profunda que el Estado mismo. Esta interioridad, esta superficie, es la población.

Habrá que esperar el surgimiento de la población como sujetoobjeto de intervención, para que las tecnologías de gobierno alcancen un nivel de sofisticación —-pero también de ambivalencia— suficiente 
para que surja lo que Gros denomina la "cuarta época de la seguridad". Con la razón de Estado aún no se conforma el campo propio de intervención, el espacio correlativo del saber gubernamental, esto lleva a Foucault (2006) a señalar que:

La población está presente cuando se pregunta: ¿Cuál es la finalidad del Estado?, y se responde: la finalidad del Estado es el Estado mismo, pero lo es en la medida en que debe ser dichoso, próspero, etc., y puede decirse entonces que la población, como sujeto $\mathrm{u}$ objeto de esa felicidad, queda ligeramente esbozada. Cuando se habla de la obediencia y se dice que el elemento fundamental de la obediencia en el gobierno es el pueblo, el pueblo que puede lanzarse a la sedición, vemos que la noción de "población" tiene una moderada presencia. Cuando se habla de público, ese público sobre cuya opinión es menester actuar a fin de modificar su comportamiento, ya estamos muy cerca de la población. Pero a mi juicio el elemento realmente deliberado de la población, la noción respectiva, no está presente ni es operativa en este primer análisis de la razón de Estado. En el fondo, se habla de una felicidad sin sujeto. (...). Se habla de riqueza, se habla de la circulación de la riqueza y de la balanza comercial [episteme clásica], pero no de la población como sujeto económico [episteme moderna]. (...) los teóricos de la razón de Estado insisten sobre el público, la necesidad de tener una opinión pública, el análisis, en cierto sentido, se hace de una manera puramente pasiva. Se trata de dar a los individuos una representación determinada, una idea determinada, imponerles algo y no valerse de su actitud, su opinión, su manera de obrar. En otras palabras, creo que la razón de Estado definió sin duda un arte de gobernar, en el cual la referencia a la población estaba implícita, pero todavía no se había incorporado justamente, al prisma reflexivo (324-325).

Ahora bien, ¿cómo ocurre la aparición de la población en el espacio correlativo de un saber? La pregunta debe plantearse de manera inversa, es decir, ¿cómo se genera un espacio enunciativo en el cual pueda aparecer una posición de sujeto semejante a la de la población? Esto ocurre debido a que el problema específico de la razón de Estado y sus ciencias particulares era delimitar su objeto propio - cuestión que había sido posibilitada ya por la episteme clásica- por lo que, a 
fuerza de "un juego incesante entre las técnicas de poder y su objeto", se "recortó poco a poco en lo real y como campo de realidad la población y sus fenómenos específicos", con lo que se posibilita que, "a partir de la constitución de la población como correlato de las técnicas de poder pudo constatarse la apertura de toda una serie de dominios de objetos para saberes posibles", al tiempo que "esos saberes recortaban sin cesar nuevos objetos, la población pudo constituirse, prolongarse, mantenerse como correlato privilegiado de los mecanismos modernos de poder" (107).

Con el quiebre epistémico ocurrido durante el siglo XVIII se remueven los cimientos de la episteme clásica. Aparecen las grandes ciencias humanas: 1) la biología como el estudio de conformación interna de las especies - y ya no el problema de la historia natural, consistente en definir los caracteres clasificatorios de las especies y su lugar en el cuadro infinito de la naturaleza-, lo que implica estudiar su consistencia anatómica y funcional, las relaciones con su medio ambiente y su carácter finito; 2) la economía política, como ciencia que analiza los modos de producción y el capital mismo - y ya no el problema del análisis de la riqueza, que se centraba en la representación de la misma a partir de la pureza de los metales preciosos y el control de la escasez y la sobreproducción-, lo que implica separar el valor de toda representación y volcarlo sobre una medida interna de las mismas mercancías: el trabajo, y 3) la filología, como el análisis de la consistencia interna de una lengua que se transforma mediante mecanismos internos $-\mathrm{y}$ el cual ya no es posible retrotraer a su capacidad para representarse en él mismo las cosas del mundo-. Esto implica que la lengua misma no es posible de retrotraerse a una raíz nominal de las cosas, sino que a la alteración interna de las palabras y los fonemas.

Por esto, la episteme moderna y las ciencias que le son correlativas pueden analizar al hombre en su individualidad y como miembro de una especie, como "ser viviente, individuo que trabaja, sujeto hablante" (108). Lo interesante de esta mutación epistémica, que se experimenta al interior de la razón de Estado, es justamente la definición del locus de tales categorías como modalidades interiores de la población, la cual se define como sujeto-objeto de intervención gubernamental. La población adquiere así una consistencia propia, cuestión sobre la cual la periodización de Gros no repara. La interioridad misma de la 
población será uno de los elementos sobre los que la intervención gubernamental moderna debe establecer su superficie de agarre: la fuerza de trabajo y los modos de producción, la biología y la relación de las especies con su medio ambiente, y el estudio de las culturas por medio de la lengua y su estructura interna (etnografía).

La población tendrá así un doble carácter: desde el punto de vista del individuo que la compone y desde el punto de vista de la masa en su impersonalidad. Su abordaje ya no podrá ser puramente negativo; su "naturaleza" densa se retirará de toda representación hacia una profundidad propia, una historicidad plegada sobre sí misma. Las técnicas de conducción de la conducta deberán ejercerse de una manera productiva, el poder deberá ser comprendido como una "acción sobre una acción, sobre acciones existente u otras que pueden suscitarse en el presente y en el futuro" (Foucault 2001253 ), exactamente como Foucault había definido el poder pastoral, es decir, un poder que se ejerce de manera productiva, capilar, individual y colectivamente, con el fin de promover e incentivar procesos de subjetivación por medio de la verdad de sí y de los otros.

\section{Conclusiones}

En este artículo revisamos la procedencia pastoral de la gubernamentalidad moderna, cuestión que desplaza la "hipótesis griega" como cuna del problema del gobierno en Occidente. En su lugar se instala la indagación en torno a un conjunto de estratos de saber y tecnologías de poder provenientes de las culturas egipcia, asiria, mesopotámica y hebrea con su idea del Dios-pastor y, por extensión, del gobernantepastor, que son retomadas y radicalizadas por los Padres de la Iglesia, al tiempo que la tradición política griega y del mundo clásico es reactualizada e indexada a un conjunto de técnicas y tecnologías de poder que no les eran propias.

En segundo lugar, hemos querido mostrar cómo las técnicas y tecnologías de poder elaboradas por el cristianismo, lejos de desaparecer con el quiebre moderno, se indexan, acoplan y relevan al interior de un nuevo conjunto estratégico, primero como "razón de Estado" y luego en torno al sujeto-objeto que se denomina "población". Con lo cual la tesis de la secularización se ve cuestionada y comprendida en lo que Foucault denomina "tecnologías de gobierno en la modernidad". 
Por tanto, el horizonte mismo trazado por las tecnologías de poder pastoral se prolongará hacia la modernidad. Esto es lo que describe Foucault (2014a) en el primer volumen de la Historia de la sexualidad, cuando, contra la hipótesis represiva del poder, asevera que el dispositivo de sexualidad desarrollado a finales del siglo XVIII e intensificado en el siglo XIX "no tiene como razón de ser el hecho de reproducir, sino el de proliferar, innovar, anexar, inventar, penetrar los cuerpos de manera cada vez más detallada y controlar las poblaciones de manera cada vez más global" (130). Tenemos así el omnes et singulatim de las tecnologías de poder pastoral: tecnologías móviles, no ajustadas a un espacio temporal determinado, individualizantes en los detalles y, al mismo tiempo, masificantes en su regulación, cuya lógica debe ser buscada por el lado de los procesos de normalización y ya no por el extremo de la normación, ya que existirán "diferentes atribuciones de normalidad y [gobernar implica] procurar que las más desfavorables se asimilen a las más favorables" (Foucault 2006 83). El siglo XVII verá aparecer la normación generalizada de una interioridad aún no visible o enunciable, y el siglo XVIII verá desarrollar una normalización generalizada de la población ${ }^{14}$ como interioridad, como espacio correlativo y superficie de inscripción y agarre de las tecnologías del poder pastoral en su deriva moderna.

La modernidad inaugura una superficie de inscripción sobre la cual podrá operar el conjunto de técnicas y tecnologías del poder pastoral de conducción de la conducta. Esta superficie es la población, relacionada profundamente a las mutaciones epistémicas que se presentan en el siglo XVIII-XIX con el nacimiento de las modernas ciencias y el nacimiento del Hombre. La figura del Hombre, como "un individuo que vive, habla, trabaja de acuerdo a leyes de una economía, de una filología y de una biología" (Foucault 1969 302), es lo que permitirá

14 Esto es lo que Foucault (2014b) señala al final del primer volumen de la Historia de la sexualidad: "Uno de los polos, al parecer el primero en formarse, fue centrado en el cuerpo como máquina: su educación, el aumento de sus aptitudes, el arrancamiento de sus fuerzas, el crecimiento paralelo de su utilidad y su docilidad, su integración en sistemas de control eficaces y económicos, todo ello quedó asegurado por procedimientos de poder característicos de las "disciplinas: anatomopolítica del cuerpo humano". El segundo, formado algo más tarde, hacia mediados del siglo XVIII, fue centrado en el cuerpoespecie, en el cuerpo transido por la mecánica de lo viviente y que sirve de soporte a los procesos biológicos: la proliferación, los nacimientos y la mortalidad, el nivel de salud, la duración de la vida y la longevidad, con todas las condiciones que pueden hacerlos variar; todos esos problemas los toma a su cargo una serie de intervenciones y controles reguladores: una "biopolítica de la población” (168). 
comprenderlo desde un doble punto de vista, es decir, desde los elementos trascendentales de la especie y los elementos empíricos e individuales, es decir, el análisis de su variación histórica y contextual. Esto le otorga a la figura del Hombre el estatuto de ser el "duplicado empírico-trascendental" (310) y vuelve coherente el saber gubernamental en su abordaje del hombre desde un punto de vista individual y a la vez masivo y totalizante, es decir, desde el punto de vista individualizante y masivo que las tecnologías del poder pastoral desarrollaron y refinaron a lo largo de, al menos, quince siglos.

La importancia de la episteme moderna, el nacimiento del Hombre y la relación que guarda la emergencia de la población es un trabajo aún por realizar. En este trabajo se ha intentado delimitar la procedencia pastoral de la gubernamentalidad y los dispositivos de poder, así como la importancia de evaluar la práctica gubernamental y política a la luz de esta larga historia de mutaciones, quizás con la esperanza de reevaluar, en lo posible, las tesis de la secularización, pero también nuestro propio "mito-griego" en torno a lo político y el problema del gobierno de los hombres, cuestión revisada por un continuador del trabajo de Foucault, a saber, Giorgio Agamben (2008), que muestra con gran claridad como el paradigma oikonomico, elaborado por los Padres de la Iglesia, parece afín con la historia política occidental más que la sola referencia a la Ciudad-Estado griega. En este sentido, este trabajo pretende ser un grano de arena en el desarrollo de dicha hipótesis sobre la base del propio texto de Foucault.

\section{Bibliografía}

Agamben, Giorgio. El Reino y la Gloria. Una genealogía teológica de la economía y del gobierno: homo sacer, II, 2. Buenos Aires: Adriana Hidalgo Editora, 2008.

Agamben, Giorgio. Opus Dei. Arqueología del oficio: homo sacer II, 5. Buenos Aires: Adriana Hidalgo Editora, 2012.

Aristóteles. Política. Madrid: Editorial Gredos, 1988.

Cacciari, M. El poder que frena. Ensayo de teología política. Buenos Aires: Amorrortu, 2015.

Castro-Gómez, Santiago. Historia de la gubernamentalidad. Razón de Estado, liberalismo y neoliberalismo en Michel Foucault. Bogotá: Siglo del Hombre Editores, 2010. 
Deleuze, Gilles. Foucault. Barcelona: Paidós, 1987.

Deleuze, Gilles. “¿Qué es un dispositivo?”. En Michel Foucault Filósofo. Barcelona: Gedisa, 1990.

Deleuze, Gilles. "Postdata sobre las sociedades de control”. El lenguaje libertario, ed. Ferrer, Christian. La Plata: Terramar, 2005. 115-121.

Deleuze, Gilles. “¿Qué es un acto de creación?”, Revista Fermentario 6 (2012): 1-16.

Foucault, Michel. Tecnologías del yo. Buenos Aires: Paidós, 2008.

Foucault, Michel. Las palabras y las cosas, una arqueología de las ciencias humanas. Buenos Aires: Siglo XXI Editores, 1968.

Foucault, Michel. "Nietzsche, la genealogía, la historia”. Microfísica del poder. Madrid: Las Ediciones de La Piqueta, 1980. 7-29.

Foucault, Michel. "Nuevo orden interior y control social”. Saber y Verdad. Madrid: Las Ediciones de la Piqueta, 1991. 163-166.

Foucault, Michel. “¿Qué es la crítica? [Crítica y Aufklärung]”, Daimon Revista Internacional de Filosofía 11 (1995): 5-26.

Foucault, Michel. "El sujeto y el poder". Michel Foucault: más allá del estructuralismo y la hermenéutica, Dreyfus, Humbert y Rabinow, Paul. Buenos Aires: Ediciones Nueva Visión, 2001. 241-260.

Foucault, Michel. Historia de la sexualidad. 3: La inquietud de sí. Buenos Aires: Siglo XXI Editores, 2003.

Foucault, Michel. Seguridad, territorio, población. Curso en el Collège de France (1977-1978). Buenos Aires: Fondo de Cultura Económica, 2006.

Foucault, Michel. Nacimiento de la biopolítica: curso en el Collège de France: 1978-1979. Buenos Aires: Fondo de Cultura Económica, 2007.

Foucault, Michel. Historia de la sexualidad. 2: El uso de los placeres. Buenos Aires: Siglo XXI Editores, 2011.

Foucault, Michel. Historia de la sexualidad, 1: La voluntad de saber. Buenos Aires: Siglo XXI Editores, 2014a.

Foucault, Michel. La hermenéutica del sujeto: Curso en el Collège de France (1981-1982). Buenos Aires: Fondo de Cultura Económica, 2014b.

Foucault, Michel. Vigilar y castigar. Nacimiento de la prisión. Buenos Aires: Siglo XXI Editores, 2018. 
Foucault, Michel. Historia de la sexualidad, 4: Las confesiones de la carne. México: Siglo XXI Editores, 2019.

Gros, Frédéric. "La cuarta edad de la seguridad". Michel Foucault: neoliberalismo y biopolítica, ed. Lemm, Vanessa. Santiago: Ediciones Universidad Diego Portales, 2012. 275-294.

Harvey, David. El nuevo imperialismo. Madrid: Ediciones Akal, 2014.

Marx, Karl. "Sobre la cuestión judía". La Cuestión Judía, Bauer, Bruno y Marx, Karl. Barcelona: Anthropos Editorial, 2019. 127-163.

Nietzsche, Friedrich. "De la genealogía de la moral". Obras completas, volumen IV. Escritos de madurez II y complementos a la edición. Madrid: Editorial Tecnos, 2016. 453-562.

Noble, David. La religión de la tecnología. La divinidad del hombre y el espiritu de invención. Barcelona: Paidós, 1999.

Platón. Diálogos, V: Parménides, Teeteto, Sofista, Político. Madrid: Editorial Gredos, 1988.

Saavedra, Juan y Marchezini, Víctor. "Procesos de recuperación posdesastre en contextos biopolíticos neoliberales: los casos de Chile 2010 y Brasil 2011". Íconos Revista de Ciencias Sociales 24/66 (2010): 131-148.

Skornicki, Arnault. "Los orígenes teológico-políticos del biopoder. Pastoral y genealogía del Estado". Sociología Histórica 5 (2015): 67-91.

Tiqqun. La hipótesis cibernética. Recuperado de: https://tiqqunim. blogspot.com/2013/01/la-hipotesis-cibernetica.html. 1999. 